\title{
A Study on the Impact of Material, Social, Symbolic Reward on OCB: Moderate Effect of the Rank
}

\author{
Woo Seok Choi, Jun Seok Heo, and Lee-Jeong Kim
}

\begin{abstract}
This study examines that reward (material, social, symbolic) which is given to employee affects the (organizational citizenship behavior OCB). We want to analyze the impact of compensation concerning the $\mathrm{OCB}$ and the moderate effect of the rank empirically. As a result of this study, the correlation of variable is partially effective between salary (material compensation), social cognition (social compensation), job importance, job interest, job challenge and OCB. The rank which is moderate variable affects strongly negative. In short, strengthening reward for freshmen improves competence of the employee and the concept of reward is more effective than other factors. Therefore we need to introduce personnel institution which includes broad material reward, social cognition, job importance, job interest, job challenge to enhance the OCB and narrow difference of the rank in service industry. After this study, we need to select subject and collect sample within extension scope. Also we need to diversify and specify the type of reward.
\end{abstract}

Index Terms-OCB, material reward, social reward, symbolic reward and rank.

\section{INTRODUCTION}

In the past, organizational members and their performance were evaluated and managed from the transactional viewpoint of mutual exchange. The recent trend, however, is that they are managed from the viewpoint of organizational human resources; thus, not only non-OCB (organizational citizenship behavior) but also $\mathrm{OCB}$ are recognized as important organizational recourses.

Reference [1] argued that for an organization to continue to survive and grow in the long term, employees should continue to participate in the organization and should conduct innovative and voluntary behaviors in addition to roles allocated to individuals; they thus emphasized the importance of OCB. This argument, based on the argument of [2], sought to enhance the whole organizational productivity and efficiency due to a growing importance of organizational human resource management.

These arguments suggest that research should focus on closely managing organizational members to induce their OCB, by shedding the past transactional viewpoint that workers' job satisfaction and organizational immersion can enhance productivity and efficiency.

Reference [3] argued that if organizational members perform only given duties, today's complicated, competitive market situations could not be effectively overcome, and that

Manuscript received October 19, 2013; revised December 21, 2013.

The authors are with the KyungPook National University, South Korea (e-mail: wschoi@knu.ac.kr, jystyle1301@knu.ac.kr, ljkim@knu.ac.kr). it is important to continuously invest in and manage not only non-OCB but also OCB in order to inspire organizational close-knit and innovative behaviors.

In addition, regarding the importance of [4] defined the meaning of OCB, and argued that OCB can help enhance team members' interdependence and create positive team achievements.

Furthermore, [5] argued that an effective wage system can motivate individuals' non-OCB and $\mathrm{OCB}$, which leads to enhanced performance. In other words, reward motivates organizational members, and has an important effect on OCB.

Thus, first, this study examines how reward (material, social and symbolic), provided to employees, - which was excluded from existing OCB studies - impacts OCB, and what sub-factors of reward have effects on OCB. Second, rank is expected to influence the relationship between reward and OCB. Thus, this study examines the moderating effect of rank on the relationship between reward and OCB.

\section{THEORETICAL BACKGROUND}

\section{A. Organizational Citizenship Behavior (OCB)}

OCB, not defined in organizational behavior regulations, means employees' voluntary behavior without reward, and can be explained in terms of a multi-dimensional concept.

Reference [6] defined the concept of OCB as: "Though not distinctively or directly recognized by the official reward system, but from the total viewpoint, individuals' discretionary behavior that effectively promotes the organization functions." He presented five sub-variables of OCB, namely, altruism, integrity, sportsmanship, etiquette, and good deed. These concepts are examined as follows.

First, altruism means individuals voluntarily helping others with their difficult work of the organization. In addition to their duties, individuals help their colleagues, thus enhancing and producing organizational efficiency. Second, integrity means the minimum level of roles and behaviors required of organizational members. Typical examples are regular attendance and keeping time strictly. Third, sportsmanship is a behavior aimed at avoiding grumbling and complaints, and basic manners of being generous to each other in the organization. Fourth, etiquette is a behavior aimed at notifying colleagues of expected organizational situations to prepare colleagues for such situations and to forecast and prevent problems. Fifth, good deed means organizational members' responsive participation in organizational situations.

Such OCB is generally defined as similar to contextual 
performance behavior, and can be explained as "contribution to maintaining and boosting social and psychological context to support task performance." Task performance is more forced duty requirement conditions, and can be better compensated for compared with OCB [7].

\section{B. Connectivity of Reward and $O C B$}

Reference [8] in his first definition of OCB, presented the characteristics of OCB as discretionary, non-compensational, and holistic. Later in 1997, he revised the non-compensation of OCB as follows: "If one performs $\mathrm{OCB}$, one expects less reward than when he engages in task performance." Thus, many researchers studied the relationship between reward and OCB.

Reference [9]-[11] argued that reward is an important motivation for individuals' behavior, and that such motivation influences job satisfaction, an antecedent, which influences OCB. Such reward is an important factor that induces organizational members' job satisfaction, and is a fundamental factor that enhances organizational immersion and motivation, thus eventually helping achieve organizational goals.

As such, reward is the antecedent of job satisfaction, organizational immersion, and motivation, which in turn is the antecedent of OCB. It can be theoretically explained that reward is an important antecedent that influences OCB.

With this theoretical explanation, [12] proved that reward influenced OCB. [13] proved the relationship between reward and OCB.

As such, reward is an important antecedent that unilaterally or interactively influences $\mathrm{OCB}$, and in recent years, research on reward-OCB relationships is being activated.

\section{Types of Reward}

Reference [14] defined reward as follows: "transaction between the organization and an individual under an employment agreement, and such transaction is mainly economic, psychological, social, political and ethical transaction." Thus, in recent years, for types of reward, not only external rewards, but also internal rewards are being weighed.

Reference [15] segmented reward into material, symbolic, and social rewards. Material reward was then segmented into remuneration, welfare benefits, guarantee of status, and working environment. Symbolic reward was segmented into diversity, importance, autonomy, fun, and challenge of duty, and opportunity for growth. Social reward was segmented into members' cohesion, mutual recognition, social recognition, boss's support, and colleagues' support.

\section{HyPOTHESES AND RESEARCH MODEL}

\section{A. Hypotheses}

This study based its hypotheses on the paper written by [16]. However, his study targeted a police organization which has strong characteristics such as stability of reward and hierarchical duties, thus probably leading to research results different from those of research on a general organization. Thus, hypotheses were revised as follows:

1) H1. Material reward will have positive effects on OCB.

- H1.1: Salary will have positive effects on OCB

- H1.2: Welfare will have positive effects on OCB

- H1.3: Promotion will have positive effects on OCB

- H1.4: Working environment will have positive effects on OCB

2) H2. Social reward will have positive effects on OCB:

- H2.1: Members acknowledgement will have positive effects on OCB

- H2.2: Social acknowledgement will have positive effects on OCB

3) H3. Symbolic reward will have positive effects on OCB.

- H3.1: Task variety will have positive effects on OCB

- H3.2: Task significance will have positive effects on OCB

- H3.3: Interesting of task

4) H4. Hierarchy will moderate the relationship between material compensation and OCB.

- H4.1: Rank will moderate the relationship between salary and OCB

- H4.2: Rank will moderate the relationship between promotion and OCB

- H4.3: Rank will moderate the relationship between welfare and OCB

- H4.4: Rank will moderate the relationship between working environment and OCB

5) H5. Hierarchy will moderate the relationship between social reward and OCB.

- H5.1: Rank will moderate the relationship between social acknowledgement and OCB

- H5.2: Rank will moderate the relationship between members acknowledgement and OCB

6) H6. Hierarchy will moderate the relationship between symbolic reward and OCB.

- H6.1: Rank will moderate the relationship between job variety and OCB

- H6.2: Rank will moderate the relationship between job significance and OCB

- H6.3: Rank will moderate the relationship between job interest and OCB

- H6.4: Rank will moderate the relationship between job challenge and OCB

- H6.5: Rank will moderate the relationship between opportunity and OCB

\section{B. Research Model}

With the establishment of hypotheses, this study aimed to identify the relationship between organizational members' OCB toward the organization or customers, and reward which is the foundation of social exchange theory.

In addition, the influence of various types of reward and their sub rewards on OCB was identified, and in order to identify the hierarchical moderation effect in such relationship between reward and OCB, a research model as shown in Fig. 1 was created. 
TABLE I: RESULT OF HIERARCHICAL REGRESSION ANALYSES (MATERIAL REWARD - OCB)

\begin{tabular}{|c|c|c|c|c|}
\hline \multirow{2}{*}{$\begin{array}{c}\text { Dependent Variable } \\
\text { Input Variable }\end{array}$} & \multicolumn{4}{|c|}{ OCB } \\
\hline & Model 1 & Model 2 & Model 3 & Model 4 \\
\hline \multicolumn{5}{|l|}{ Step1: Control Variable } \\
\hline $\operatorname{sex}$ & $0.061(.343)$ & $0.035(.591)$ & $0.018(.779)$ & $0.001(.993)$ \\
\hline age & $0.098(.259)$ & $0.126(.167)$ & $0.132(.133)$ & $0.101(.257)$ \\
\hline continuous service month & $0.020(.771)$ & $0.048(.501)$ & $0.020(.783)$ & $0.026(.721)$ \\
\hline \multicolumn{5}{|l|}{ Step 2: Independent Variable } \\
\hline salary & & $0.197(.048)^{* *}$ & $0.077(.440)$ & $0.845(.051)^{*}$ \\
\hline promotion & & $0.040(.617)$ & $0.107(.171)$ & $0.034(.907)$ \\
\hline welfare & & $0.122(.209)$ & $0.156(.099)^{*}$ & $0.374(.407)$ \\
\hline working environment & & $0.010(.897)$ & $0.011(.884)$ & $0.346(.280)$ \\
\hline \multicolumn{5}{|l|}{ Step 3 : Moderating Variables } \\
\hline rank & & & $-0.294(.000)^{* * *}$ & $0.462(.168)$ \\
\hline \multicolumn{5}{|l|}{ Step 4 : Moderating Effect } \\
\hline salary $\times$ rank & & & & $1.587(.067) *$ \\
\hline promotion $\times$ rank & & & & $153(.746)$ \\
\hline welfare $\times$ rank & & & & $0.484(.558)$ \\
\hline working environment $\times$ rank & & & & $0.664(.224)$ \\
\hline$R^{2}$ & 0.008 & 0.031 & 0.099 & 0.153 \\
\hline$\Delta R^{2}$ & 0.008 & 0.023 & 0.068 & 0.055 \\
\hline Adjusted $\mathrm{R}^{2}$ & -0.008 & 0.000 & 0.067 & 0.106 \\
\hline$F$ & 0.497 & 1.005 & $3.085^{* * *}$ & $3.223^{* * *}$ \\
\hline$\Delta F$ & 0.497 & 1.510 & $19.152 * * *$ & $3.228 * *$ \\
\hline
\end{tabular}

TABLE II: RESUlT OF HIERARCHICAL REGRESSION ANALYSES (SOCIAL REWARD - OCB)

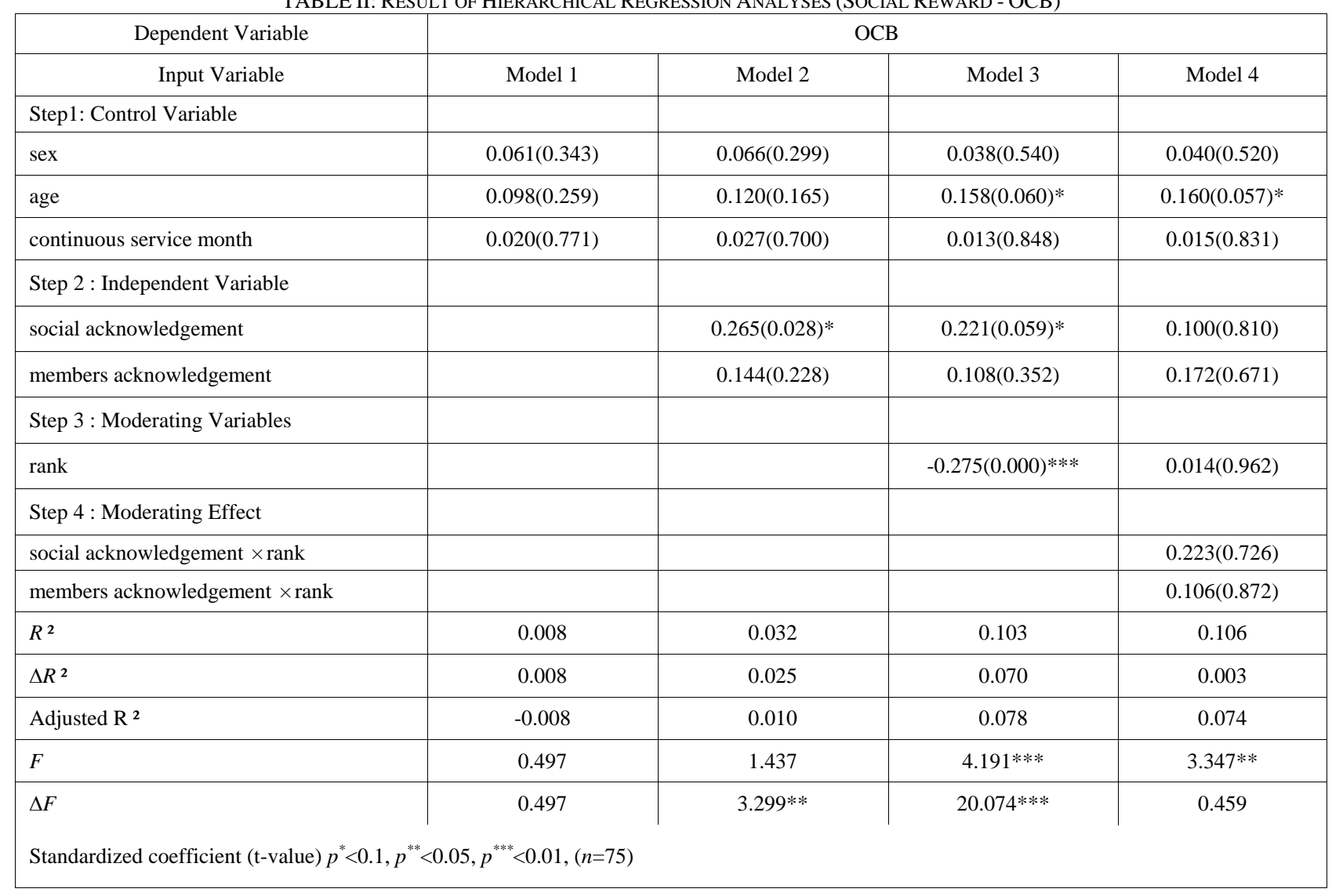


TABLE III: RESULT OF HIERARCHICAL REGRESSION ANALYSES (SYMBOLIC REWARD - OCB)

\begin{tabular}{|c|c|c|c|c|}
\hline Dependent Variable & \multicolumn{4}{|c|}{ OCB } \\
\hline Input Variable & Model 1 & Model 2 & Model 3 & Model 4 \\
\hline \multicolumn{5}{|l|}{ Step1: Control Variable } \\
\hline $\operatorname{sex}$ & $0.061(0.343)$ & $0.063(0.323)$ & $0.040(0.517)$ & $0.040(0.528)$ \\
\hline age & $0.098(0.259)$ & $0.067(0.441)$ & $0.101(0.231)$ & $0.089(0.303)$ \\
\hline continuous service month & $0.020(0.771)$ & $0.041(0.564)$ & $0.018(0.797)$ & $0.012(0.864)$ \\
\hline \multicolumn{5}{|l|}{ Step 2 : Independent Variable } \\
\hline job variety & & $0.021(0.789)$ & $0.045(0.552)$ & $0.284(0.380)$ \\
\hline job significance & & $0.182(0.087)^{*}$ & $0.154(0.131)$ & $0.444(0.246)$ \\
\hline job interest & & $0.137(0.062)^{*}$ & $0.173(0.015)^{* *}$ & $0.037(0.890)$ \\
\hline job challenge & & $0.198(0.080)^{*}$ & $0.123(0.263)$ & $479(0.323)$ \\
\hline opportunity of growth & & $0.088(0.238)$ & $0.100(0.165)$ & $210(0.490)$ \\
\hline \multicolumn{5}{|l|}{ Step 3 : Moderating Variables } \\
\hline rank & & & $-0.301(0.000)^{* * *}$ & $0.406(0.236)$ \\
\hline \multicolumn{5}{|l|}{ Step 4 : Moderating Effect } \\
\hline job variety $\times$ rank & & & & $0.642(0.280)$ \\
\hline job significance $\times$ rank & & & & $0.619(0.406)$ \\
\hline job interest $\times$ rank & & & & $0.337(0.444)$ \\
\hline job challenge $\times$ rank & & & & $0.718(0.432)$ \\
\hline opportunity of growth $\times$ rank & & & & $0.198(0.693)$ \\
\hline $\mathrm{R}^{2}$ & 0.008 & 0.042 & 0.118 & 0.130 \\
\hline$\Delta \mathrm{R}^{2}$ & 0.008 & 0.035 & 0.075 & 0.013 \\
\hline Adjusted $\mathrm{R}^{2}$ & -0.008 & 0.009 & 0.083 & 0.078 \\
\hline $\mathrm{F}$ & 0.497 & 1.252 & $3.383 * *$ & 2.480 \\
\hline$\Delta \mathrm{F}$ & 0.497 & 1.849 & $21.646 * *$ & $0.713 * *$ \\
\hline
\end{tabular}

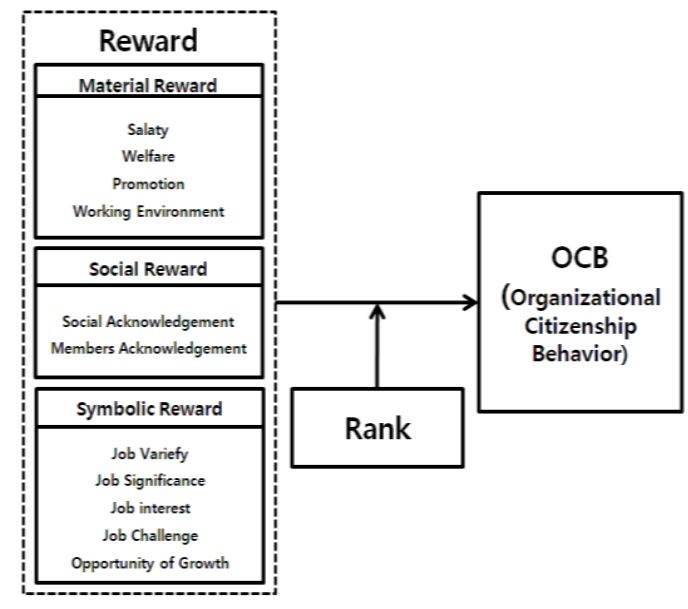

Fig. 1. Moderate effect of rank in the relationship between materials, social, symbolic and OCB.

All tables shows the results of hierarchical regression analysis.

Table I shows that relationship between OCB and Material Reward which one of Reward's sub-factor. Model 1-3 are analysis results that control variable (step1), Material Reward(step2) and Rank(step3) affect OCB. Model 4 verifies Material Reward*Rank (step4) moderation effect about relationship between Material Reward and OCB.

Table II shows that relationship between OCB and Social Reward which one of Reward's sub-factor. Model 1-3 are analysis results that control variable (step1), Social Reward (step2) and Rank (step3) affect OCB. Model 4 verifies Social Reward*Rank (step4) moderation effect about relationship between Social Reward and OCB.

Table III shows that relationship between OCB and Symbolic Reward which one of Reward's sub-factor. Model 1-3 are analysis results that control variable (step1), Symbolic Reward (step2) and Rank (step3) affect OCB. Model 4 verifies Symbolic Reward*Rank (step4) moderation effect about relationship between Symbolic Reward and OCB.

\section{MEASURE}

\section{A. Sampling and Data Collection}

300 people in the service sector were surveyed to identify the effects of reward on OCB and rank's moderating effects. Of the 300 answered questionnaire copies, 264 (88\%) except 
erroneous 36 copies were used in the study.

264 copies were individually coded, and the data were analyzed statistically using the SPSS WIN 18.0.

For statistical treatment, data underwent reliability and validity analysis, and in order to identify the causation between individual reward types and OCB, hierarchical regression analysis was performed. Also, to prevent common method bias, common method variance test was conducted.

\section{B. Method}

The chief aim of this article is to investigate the causal relationship between reward (material, social, symbolic) and OCB. We aim to confirm a moderating effect of rank. We use regression analysis to unearth the nature of the causal relations that we address in our study. Therefore we will devide each causal relationship (variable of control, independent, moderate and independent*moderate) between reward (material, social, symbolic) and OCB. This is to be done through statistical techniques of hierarchical regression analysis. We aim to verify the original influence of each variable.

\section{Common Method Variance}

Common method bias may occur when surveying respondents in the same category like this study. To check such bias, Harman's one-factor-test of independent variable, dependant variable, and moderating variable except control variable (demographic factor) was performed. The factor analysis of dependent variables and moderating variables revealed this: Each independent variables had 5, 5 and 2 factors with Eigen value of over 1, and the factor variance was 59\% 92\%. Although the explanatory variance frequency was somewhat high, single factors were not derived, and the dependent variable OCB also had 5 factors with Eigen value of over 1 . The first factor had a variance of $75 \%$; thus, common method bias problems were not deemed to be serious.

\section{RESULTS}

\section{A. Hierarchical Regression Analysis}

To verify the individual hypotheses in detail, hierarchical regression analysis was performed. Step 1 measured the basic control variable demographic factors (sex, age, continuous service month). Step 2 measured independent variables (material reward, social reward, and symbolic reward). Step 3 measured the moderating variable rank. To measure the interaction between the independent variables and the moderating variable, step 4 multiplied measured individual independent variables' sub factors by the moderating variable's sub factors, and created and measured interactive variables.

\section{1) Material reward - OCB regression analysis}

The relationship between the major material-reward variable salary and the dependent variable OCB was $\beta=0.197$ $p<0.05$, thus showing an effective positive (+) relationship. However, promotion, welfare, and working environment did not show a significant positive relationship with OCB.

Of the sub factors of hypothesis 4 of "rank will moderate the relationship between material reward's sub variables and OCB," only the remuneration and rank interaction $(\beta=1.587$, $p<0.1)$ had a significant effect.

\section{2) Social reward-OCB regression analysis}

The relationship between the major social-reward variable social acknowledgement and the dependent variable OCB was $\beta=0.265, p<0.1$, thus showing an effective positive (+) relationship. However, members acknowledgement did not show a significant positive relationship with OCB.

Also, rank did not have a moderating effect on the relationship between social reward and OCB.

\section{3) Symbolic reward-OCB regression analysis}

Of symbolic reward's sub factors, job significance $(\beta=0.182, p<0.1)$, job interest $(\beta=0.137, p<0.1)$, and job challenge $(\beta=0.198, p<0.1)$ had weak yet significant positive $(+)$ effect on OCB.

However, rank did not have a moderating effect on the relationship between symbolic reward and OCB.

\section{CONCLUSION}

The study examined the effects of the three types of reward (material, symbolic and social rewards), provided to organizational members in the service industry, on OCB. Rank's moderating effect on these relationships was examined to formulate detailed efficient HR management measures.

According to the findings of this study, promoting OCB activity were remuneration (a subfactor of material reward), social recognition (a subfactor of social reward), and the importance of duty, fun of duty, and challenge of duty (subfactors of symbolic reward). Also, rank had a moderating effect only on the relationship between remuneration and OCB. Derived from these results were the following implications.

First, with an increasing amount of salaries, OCB activity increases, but this effect is reduced in higher ranks. In other words, the HR management of boosting OCB activity through remuneration is suited to low-ranking employees.

Second, social recognition for organizational members, regardless of ranks, triggers OCB. This means that for many organizational members, recognition from colleagues promotes their performance.

Third, if a person's duty is regarded as important in the organization, and if that duty satisfies his interest and pioneering mindset, it will, regardless of remuneration, trigger members' OCB.

Putting together these implications, efficient HR management of organizational members can be conducted through reward. However, such reward is not the matter of selecting material, social or symbolic rewards, but should be target-oriented. This suggests that organizational HR management measures should not be uniform but flexible according to organizational members' ranks. For new employees, remuneration-focused HR management measures are more effective; thus the organizational effective resource OCB should be activated through remuneration for performance. However, for managers or higher-ranking organizational members, measures should be taken to boost 
their sense of achievement and stability, to let them recognize the importance and fun of their jobs, and to encourage them to take on challenges.

Herein, reward was examined as the antecedent of OCB. However, it is not clear which is first, reward or OCB. Thus, this point could not be clearly identified herein.

Therefore, future research should study reward as the resulting factor of OCB. In addition to reward, other diverse antecedents, which may have effects on OCB, as well as moderating and mediating factors should be further studied. Longitudinal study should be conducted to examine the causation between early and late behaviors

\section{REFERENCES}

[1] P. Cappelli and N. Rogovsky, "Employee Involvement and organizational citizenship: implications for labor law reform and lean production," Industrial and Labor Relations Review, vol. 51, no. 4, pp. 633-653, 1998

[2] D. Kaze, "The motivational basis of organizational behavior," Behavior Science, no. 9, pp. 131-133, 1964.

[3] H. J. Hee and J. J. Chul, "The relationship between job characteristics and OCB with moderating effect of career-related characteristics," Productivity Review, vol. 15, no. 1, pp. 249-269, 2001.

[4] K. K. Seok and M. H. Koo, "Suggestions for the Studies on Non-task Behavior," Korean Academy of Organization and Management, vol. 29, no. 4, pp. 1-30, 2005.

[5] E. E. Lawler, Strategic Pay: Alingning Organizational Strategies and PAY Systems, sanfrancisco: Josse-Bass, 1990.

[6] D. W. Organ, Organizational Citizenship Behavior: The Good Soldier Syndrom, Lexington, MA: Lexington Books, 1988.

[7] K. K. Seok, "A configurational approach to organizational citizenship behavior," Ph.D. dissertation, Dept. of Business Administration. Kor., Graduate School of Korea Univ., Seoul, South Korea, 2004.

[8] D. W. Organ, "Organizational Citizenship Behavior: It's Construct Clean-Up Time," Human Performance, vol. 10, no. 2, pp. 85-97, 1997.

[9] S. M. Lee, "An empirical analysis of organizational identification," Academy of Management Journal, vol. 14, no. 2, pp. 213-226, 1971.

[10] J. R. Hackman and G. R. Oldham, Work Redesign. Reading, MA: Addison-Wesley, 1980.

[11] K. J. Wook and J. I. Bong "A study on the determinants of affective, continuance, and normative commitment to the organization," Korean Public Administration Review, vol. 38, no. 5, pp. 327-349, 2004

[12] J. R. Deckop, R. Mangel, and C. C. Crika, "Getting more than you pay for: Organization citizenship behav ior and pay-for performance plans," Academy of Manadement Journal, vol. 39, no. 4, pp. 420-428, 1999.

[13] C. W. Seok, "An empirical study on the effect of Wage Equity Perception upon the organizational citizenship behavior: Focusing on moderating effect of trust types," M.S. thesis, Dept. of Business Administration. Kor., Graduate School of Hanyang Univ., Seoul, South Korea, 2007.
[14] D. W. Belcher and T. J. Atchison, "Compensation administration," in Englewood Cliffs, NJ: Prentice-Hall, 1974

[15] R. Katz and J. V. Maanen, "The loci of work satisfaction: Job, interaction, and policy," Human Relations, vol. 30, no. 5, pp. 469-486, 1977.

[16] Y. Y. Hyun, "A study on the organizational commitment according to the type of compensation: Focused on the police officers," Korean Academy of Human Resource Management, vol. 14, no. 1, pp. 129-148, 2007.

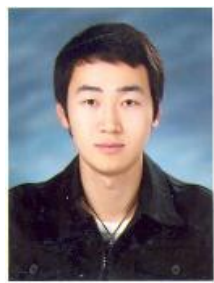

Woo Seok Choi was born in Daegu, South Korea, on May 21, 1983. He earned a master's degree a Kyungpook National University in 2011. Since 2009, he has been a researcher at KNU Industrial Policy Research Institute. Currently, $\mathrm{He}$ is in the Doctoral course at KNU, and a senior researcher. His other experience includes teaching the student at Korea Poly-Tech University. In 2012, he presented his dissertations in ICOSH. He was research and published his dissertations in The korea Journal of Sports Science, Korean Society of Sport and Leisure Studies. His major research areas include Creative Economy, Industrial Policy, Management of Technology, Technology Commercialization, Technology Innovation, Open Innovation, Cluster. In this connection, his main research is analysis of actual proof on 'Job Creation Policy of korea in Creative Economy', 'Global Strategy of Convergence and Integration Corporation'.



Jun Seok Heo was born in Gyeongsan City, South Korea, on August 1, 1981. He earned a master's degree at Kyungpook National University in 2013. Currently, he is in the Doctoral course at KNU. Since 2011, he has been a researcher at KNU Culture Industry Research Institute. Currently, he is a senior researcher. In 2012 he presented his dissertations in three overseas symposiums. His major research areas include corporate ecosystems, platform strategy, win-win growths between firms, and creative economy. In this connection, he conducted case studies on Samsung Electronics, CJ and KT.

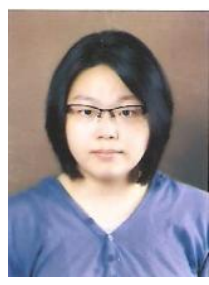

Lee-Jeong Kim was born in Daegu City, South Korea, on February 20, 1990. She received a bachelor of business administration from Yeung-Jin College in 2013. Since 2013, She has been a researcher at KNU Culture Industry Research Institute. Currently, She is in the Master course at Kyungpook National University. She's major research areas include Creative Economy, organizational management and strategic management. 